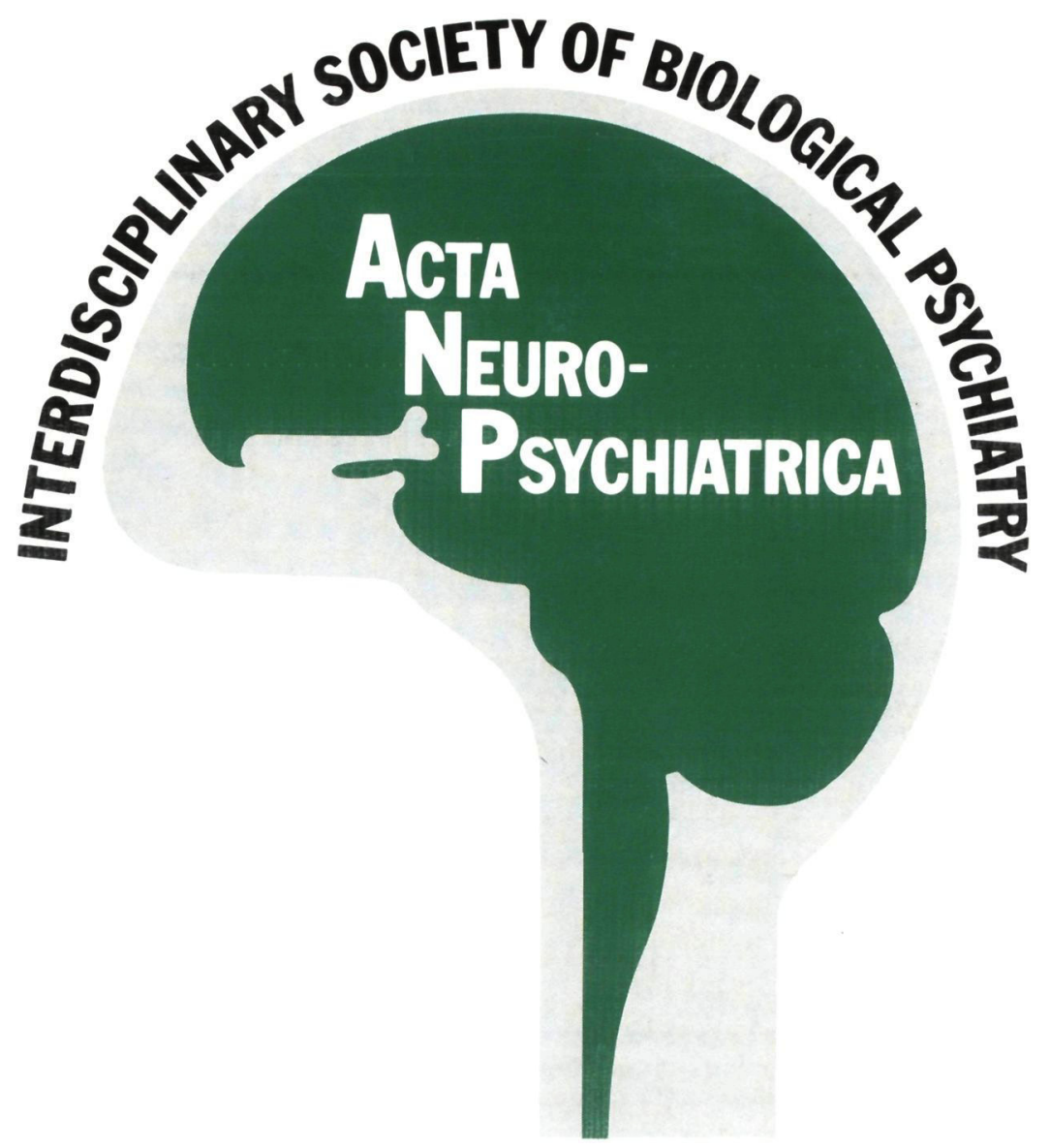

Acta Neuropsychiatrica

OFFICIEEL WETENSCHAPPELIJK ORGAAN VAN HET I G B P (INTERDISCIPLINAIR GENOOTSCHAP VOOR BIOLOGISCHE PSYCHIATRIE)

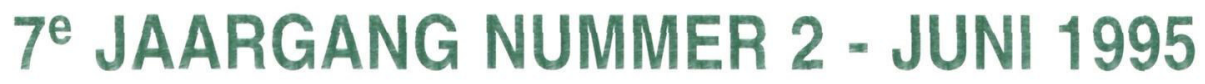

\title{
CONGRESS PROCEEDINGS
}

'Rhythms, Behaviour and Mood'

In honour of Prof. dr. R.H. van den Hoofdakker, on the occasion of his retirement 


\section{CONTENTS}

From the editor

From the board

Sleep regulation: physiological models and hypotheses

\section{A.A. Borbély}

Circadian tuning of motivation. A little organ of yesterday?

S. Daan

Circadian regulation of sleep propensity, sleep structure and alertness: A symphony of paradoxes D.J. Dijk

Social stress in rats: An animal model of depression?

J.M. Koolhaas, P. Meerlo, S.F. de Boer, J.H. Strubbe, B. Bohus

An interpersonal view on depression

A.L. Bouhuys, E. Geerts, P.P.A. Mersch, J.A. Jenner

Functional brain imaging, sleep, and sleep deprivation: Contributions to the "overarousal" hypothesis of depression

J.C. Gillin, A.P. Ho, M.S. Buchsbaum, J. Wu, L. Abel, W.E. Bunney, Jr.

Response of human melatonin secretion to changes in nightlength (scotoperiod):

Implications for seasonal affective disorder and other psychiatric illnesses

T.A. Wehr

Spectral analysis of the sleep EEG of depressed patients before and after total sleep deprivation

D.G.M. Beersma, R.H. van den Hoofdakker

Circadian rhythms and sleep regulation in seasonal affective disorder

A. Wirz-Justice, K. Kräuchi, D.P. Brunner, P. Graw, H.-J. Haug, G. Leonhardt, A. Sarrafzadeh,

J. English, J. Arendt

Treatment indications for light therapy

S. Kasper, A. Neumeister

The prevalence of seasonal affective disorder (SAD) in the Netherlands

P.P.A. Mersch, H. Middendorp, A.L. Bouhuys, D.G.M. Beersma, R.H. van den Hoofdakker

Treating depression with sleep deprivation and consecutive sleep phase advance therapy

M. Berger, J. Vollmann, F. Hohagen, A. König, H. Lohner, D. Rlemann

The clinical relevance of treatment with antidepressants

W.A. Nolen

Biological theories of depressions: premisses - and progress?

W. van den Burg

A longitudinal study of sleep deprivation responses in depression;

The variability is highly related to diurnal mood variability

M.C.M. Gordijn, D.G.M. Beersma, A.L. Bouhuys, H.J. Korte, R.H. van den Hoofdakker

The timing of light therapy and response assessment in winter depression

\section{Y. Meesters}

Attunement of non-verbal behaviour between depressed patients and a psychiatrist at admission

E. Geerts, A.L. Bouhuys, R.H. van den Hoofdakker

Lithium treatment in affective disorders: The significance of strongly elevated erythrocyte choline levels

F. Flentge, C.J. Slooff

The rat hippocampus as a target for prolonged stress: Biochemical and behavioral effects 


\section{ACTA NEUROPSYCHIATRICA}

Officieel orgaan van het Interdisciplinair Genootschap voor Biologische Psychiatrie

ISSN 0924-2708

Reed HealthCare

Van de Sande Bakhuyzenstraat 4,

1061 AG Amsterdam.

Postadres: Postbus 1126, 1000 BC Amsterdam.

Tel.: $31-(0) 20-5153356$.

Fax: $31-(0) 20-5153354$.

\section{Redactie}

Prof.dr. A.R. Cools

Prof.dr. H.A.H. D'haenen

R.S. Kahn

Prof.dr. J. Korf

dr. M. Maes

Prof.dr. H.M. van Praag

Hoofdredactie

dr. M.J.A.J.M. Hoes

Eindredactie

Mw. S.J.M. Wernars

Redactiesecretariaat

Reed HealthCare

Postbus 1126,

1000 BC Amsterdam.

Tel.: $31-(0) 20-5153351$.

Fax: $31-(0) 20-5153354$.

Advertenties: Voor alle inlichtingen

Reed HealthCare

Postadres: Postbus 1126,

1000 BC Amsterdam.

Tel.: 31 -(0)20-5153350.

Abonnementen: Kunnen ieder moment worden aangegaan voor minimaal één jaar en worden stilzwijgend telkens voor een jaar verlengd, indien niet minimaal zes weken voor afloop een opzegging is ontvangen.

Voor Nederland $f 60$,- incl. BTW.

Voor Europa $f$ 75,-p.a.; psychiaters in opleiding $f$ 37,50. Leden van het IGBP en psychiaters in opleiding ontvangen Acta Neuropsychiatrica gratis.

Overige landen $f 90$,- p.a.

Abonnementsgeld overmaken naar nr. 210000 (Postbank) ten name van Excerpta Medica Medical Communications B.V., Van de Sande Bakhuyzenstraat 4, 1061 AG Amsterdam.
Losse nummers: $f$ 20,- per stuk incl. BTW en verzendkosten.

Frequentie $4 \times$ per jaar.

Copyright:

\section{Reed HealthCare}

Niets uit deze uitgave mag worden gefotocopiëerd en/of verveelvoudigd zonder voorafgaande schriftelijke toestemming van de uitgever.

Acta Neuropsychiatrica is het officiële orgaan van het Interdisciplinair Genootschap voor Biologische Psychiatrie (IGBP).

Redactie-adviesraad

Prof.dr. H. Van Den Berghe, Leuven

Prof.dr. B. Bohus, Haren

Prof.dr. R.J. van den Bosch, Groningen

Prof.dr. C.H.M. Brunia, Tilburg

Prof.dr. E.J. Colon, Poortugaal

Prof.dr. P. Cosyns, Edegem

Dr. M. Danhof, Leiden

Dr. M.P. Derde, Brussel

Prof.dr. P. Eikelenboom, Amsterdam

Prof.dr. J. Godderis, Leuven

Dr. W.P. Haaijman, Lent

Prof.dr. R.H. van den Hoofdakker, Groningen

Prof.dr. B.Van Houdenhove, Leuven

Prof.dr. J. Jolles, Maastricht

Prof.dr. L. Kaufman, Brussel

Prof.dr. J. De Keyser, Brussel

Drs. G.A.S. Koster van Groos, Rosmalen

Dr. A.J.M. Loonen, Vught

Prof.em.dr. A. Lowenthal, Antwerpen

Dr. P. Moleman, Amerongen

Prof.dr. M. Niermeyer, Rotterdam

Prof.em.dr. R. Nieuwenhuys, Abcoude

Dr. W.A. Nolen, Utrecht

Prof.dr. S.J. Nijdam, Milsbeek

Prof.dr. G.W.A.M. Padberg, Nijmegen

Prof.dr. J. Peuskens, Kortenberg

Prof.dr. J.M. van Ree, Utrecht

Prof.dr. J. De Roeck, Edegem

Dr. C.J. Slooff, Groningen

Prof.dr. E. Thierry, Gent

Prof.dr. F. Tilders, Amsterdam

Prof.dr. D.H.G. Versteeg, Utrecht

Dr. T.B. Vree, Nijmegen

Dr. H.G.M. Westenberg, Utrecht

Dr. T.C.A.M. van Woerkom, Den Haag

Dr. E. Ch. Wolters, Amsterdam

Prof.dr. F.G. Zitman, Nijmegen 


\section{INFORMATIE VOOR AUTEURS}

Het doel van de Acta Neuropsychiatrica (Acta Neuropsychiat.) is het bevorderen van de kennis en het gebruik van neuropsychiatrische gegevens in de dagelijkse medische praktijk in het Nederlandse taalgebied. Onder neuropsychiatrie wordt verstaan de studie en toepassing van de wetenschappelijk gefundeerde kennis en ervaring van de relatie tussen het zenuwstelsel en psychiatrische stoornissen. Daarom dient de klinische relevantie van artikelen op de voorgrond te staan. Het tijdschrift volgt de meest recente editie van 'Uniform requirements for manuscripts submitted to biomedical journals' (zie B med J 1991; 302:338-41). De volgende richtlijnen worden aan de inzender van kopij extra onder de aandacht gebracht.

1. Overzichtsartikelen en origineel onderzoek worden door de redactie in beoordeling genomen. Aanbieding bij de Acta Neuropsychiat. impliceert dat het manuscript niet tegelijkertijd elders is aangeboden ter beoordeling, is geaccepteerd of gepubliceerd.

2. Men dient te overleggen een schriftelijke verklaring waaruit blijkt:

a. dat een goedkeuring is verkregen voor het onderzoeksverslag door de plaatselijke ethische commissie, informed consent, confirmering aan de Verklaring van Helsinki.

b. de accordering van personen die als 'persoonlijke mededeling' worden geciteerd;

c. toestemming van de auteur en de uitgever van eerder gepubliceerd en overgenomen materiaal;

d. de accordering van alle auteurs en andere personen die met name in of bij het artikel als contribuant genoemd worden (een auteur is iemand die aanzienlijk heeft bijgedragen aan zowel a) ontwerp van de studie of analyse en interpretatie van de resultaten, als aan b) het schrijven of herzien van het manuscript en c) het aangeboden manuscript heeft goedgekeurd. Uitsluitende deelname aan fondswerving of aan het verzamelen der gegevens rechtvaardigt geen auteurschap).

3. Door inzending van de kopij stemt de auteur ermee in dat de volledige auteursrechten ingeval van acceptering van het manuscript aan de uitgever van Acta Neuropsychiat. zijn overgedragen. Tevens is men akkoord dat de redactie voor het manuscript extern advies kan inwinnen.

4. Vervaardig het manuscript met typemachine of printer op degelijk A4 papier met $2,5 \mathrm{~cm}$ marges en dubbele interlinie. Begin op een nieuw vel met:

- titelpagina (titel artikel, titel namen en werkplaats van auteurs, eventuele dankbetuiging, correspondentie-adres van één auteur met telefoonnummer eventueel telefaxnummer), financiers,

- samenvatting in het Nederlands (max. 150 woorden; doel onderzoek, gehanteerde procedures, belangrijkste resultaten, voornaamste conclusies; vermeld nieuwe en belangwekkende aspecten van het onderzoek) met 3 à 10 sleutelwoorden, werktitel (max. 3 woorden),

- Engelstalige titel, summary en key-words,

- inleiding,

- materiaal en methode( $n$ ),

- resultaten (statistische bewerkingen dienen op grond van de vermelde gegevens te kunnen worden nagerekend),

- discussie,

- literatuur,

- titel en legenda figuren en tabellen (de laatste nummeren met romeinse cijfers),

- legenda bij figuren en tabellen in het Engels en het Nederlands.

Doublures van figuren en tabellen dienen te worden vermeden.

Nummer alle pagina's in de rechterbovenhoek en geef in de kantlijn duidelijk aan waar de figuren en tabellen dienen te worden geplaatst. Elk van beide artikelen sub I mogen niet langer zijn dan 3000 woorden, inclusief figuren, tabellen en literatuur. Men hantere de voorkeurspelling volgens de meest recente editie van de dikke van Dale. De "ik" of "wij" vorm dient te worden vermeden.

5. De literatuur wordt genummerd op volgorde van citering in de tekst. In de tekst worden referenties met nummer (in superscript) en niet met naam vermeld.

De redactie adviseert $u$ de referenties bij een artikel tot 25 referenties te beperken.

6. Figuren dienen als glanzende zwart-witfoto's in enkelvoud te worden aangeleverd, verpakt op karton. Kleurenfoto's worden geplaatst indien de auteur de lithokosten bij acceptatie van het manuscript voldoet. Alle illustraties dienen in de rechterbovenhoek aan de achterkant in zacht potlood de naam van de eerste auteur en het figuurnummer te dragen .

7. Alle kopij wordt tenminste door de redactie beoordeeld. De auteur ontvangt bericht van ontvangst van het manuscript en krijgt binnen twee maanden daarna bericht over de beoordeling van het manuscript. De redactie behoudt zich het recht voor waar nodig de stijl van het manuscript bij te stellen vanwege de uniformering voor het Tijdschrift.

8. Medicamenten of farmaca worden met generische naam vermeld. Bij eerste vermelding worden tussen twee haakjes alle merknamen van de stof in Nederland en/of België éénmalig vermeld.

9. De auteur ontvangt kosteloos vijf extra nummers van de aflevering van de Acta waarin zijn artikel geplaatst is, meestal binnen enkele weken na de publikatie. Hij kan bij acceptatie van zijn manuscript één of meerder honderdtallen overdrukjes voor eigen rekening bestellen. Deze dienen vier weken voor publikatie van het manuscript te zijn voldaan bij de Uitgever.

10. Men zendt het origineel en 3 deugdelijke kopieën en gaarne een diskette van het definitieve manuscript naar het redactiesecretariaat, t.a.v. mevrouw S.J.M. Wernars, Postbus 1126, 1000 BC Amsterdam. Het begeleidend schrijven dient de volgende informatie te bevatten:

a. Eventuele eerdere of dubbele publikatie of aanbieding van een deel of delen van de studie,

b. financiële of andere belangen die tot een belangenconflict kunnen leiden,

c. naam, adres, telefoon- en eventueel telefaxnummer van de corresponderende auteur.

d. verklaring dat de auteur de voorwaarden onder 1, 2 en 3 onderschrijft. 